\title{
Rates of periprosthetic infection and surgical revision in Beijing (China) between 2014 and 2016: a retrospective multicenter cross-sectional study
}

\author{
Hui-ming Peng ${ }^{1 \dagger}$, Long-chao Wang ${ }^{1 \dagger}$, Ji-ying Cheng ${ }^{2}$, Yi-xin Zhou ${ }^{3}$, Hua Tian ${ }^{4}$, Jian-hao Lin ${ }^{5}$, Wan-shou Guo ${ }^{6}$, \\ Yuan Lin', Tie-bing Qu ${ }^{8}, \mathrm{Ai} \mathrm{Guo}^{9}$, Yong-ping Cao ${ }^{10}$ and Xi-sheng Weng ${ }^{1 *}$
}

\begin{abstract}
Background: Periprosthetic joint infection (PJI) is a rare but devastating complication after total joint arthroplasty. There is a paucity of data on the incidence and prevalence of periprosthetic infection in mainland China. This study aimed to analyze the rates of surgical revision after arthroplasty due to PJI and the procedures followed in Beijing, China.

Methods: The study involved a retrospective multicenter cross-sectional survey of patients undergoing revisions for periprosthetic infection after hip/knee arthroplasty at nine hospitals in Beijing from 2014 to 2016. Age, gender, body mass index, primary diagnosis, comorbidity, primary surgery, treatment methods, and post-revision complications were analyzed.

Results: A total of 38,319 hip/knee arthroplasties and 366 (0.96\%) revisions for PJl were identified. Of these, 161 (161/14,110; 1.14\%) revisions involved hip arthroplasty, whereas 205 (205/24,209; 0.85\%) revisions were due to knee arthroplasty. Procedures for revisions of infected hip included 7 (4.3\%) cases of open debridement and prosthesis retention, 32 (19.9\%) cases of one-stage exchange, 121 (75.2\%) cases of two-stage exchange, and $1(0.007 \%)$ case of hip dissection. As for the infected knee, the procedures included 45 (22.0\%) cases of open debridement and prosthesis retention, 13 (6.3\%) cases of one-stage exchange, 143 (69.8\%) cases of two-stage exchange, and $4(0.02 \%)$ cases of knee fusion.

Conclusions: The study found the rates of revision due to PJI to be low. Nonetheless, the incidence of PJI in mainland China could be higher and calls for more elaborate studies in geographically and socioeconomically diverse health institutions.
\end{abstract}

Keywords: Arthroplasty, Hip and knee replacement, Infection, Revision

\section{Background}

Hip or knee arthroplasty is often the last recourse in the treatment of terminal hip and knee diseases. In the UK and the USA, approximately 800,000 joint replacement surgeries are performed annually, and this number is expected to exceed 4 million by the year 2030 [1].

\footnotetext{
*Correspondence: xshweng_med@126.com

${ }^{\dagger}$ Hui-ming Peng and Long-chao Wang contributed equally to this work.

'Department of Orthopedics, Peking Union Medical College Hospital, CAMS \& PUMC, No.1 Shuaifuyuan, Wangfujing, Dongcheng District, Beijing 100730, China

Full list of author information is available at the end of the article
}

Periprosthetic joint infection (PJI) is a potentially devastating complication after joint replacement. This condition is associated with pain, compromised joint function, prolonged hospitalization, and increased cost of medical care. In some cases, high patient mortality has been reported $[2,3]$. Treatment options for periprosthetic infection include debridement, use of antimicrobials, and surgical revision with the aim to restore joint function and relieve pain [4-6]. Surgical revisions and other treatments for PJI are expensive. For example, in the USA alone, the estimated cost of treating

(C) The Author(s). 2019 Open Access This article is distributed under the terms of the Creative Commons Attribution 4.0 International License (http://creativecommons.org/licenses/by/4.0/), which permits unrestricted use, distribution, and 
periprosthetic infection was 566 million dollars in 2009 and is estimated to reach 1.62 billion dollars by the year 2020 [7].

The reported incidence of periprosthetic infection in the Western populations is 1.2-2.2\% [8-10]. On the other hand, there is a paucity of data on the incidence of periprosthetic infection after hip or knee arthroplasty in China. This is likely due to the far more recent development of technical capacity to conduct joint replacement surgery in China. Our study, therefore, aimed to analyze the incidence and management of PJI at 9 main arthroplasty centers in Beijing, China. Data was collected retrospectively for the time period between 2014 and 2016. The nine selected centers are the top referral hospitals in Beijing with high surgical volumes of at least 500 artificial joint replacement surgeries per year.

\section{Methods}

\section{Patients}

Clinical data of patients diagnosed with PJI following hip/knee arthroplasty were collected retrospectively for the time period between 1 January 2014 and 31 December 2016 in the nine health institutions that serve as main arthroplasty centers in Beijing, China. Primary surgeries were hip arthroplasty (including total hip arthroplasty and femoral head replacement) and knee arthroplasty (including total knee arthroplasty and partial knee arthroplasty). The treatment options for periprosthetic infection included open debridement with retention of the prosthesis, one-stage or two-stage revision, and hip disarticulation and hip/knee joint fusion.

\section{Data collection}

Demographic and clinical data included age, gender, body mass index (BMI), primary diagnosis, and preoperative comorbidities. Surgical methods, the occurrence of periprosthetic infection (type of infection, sinus tract involvement, etiological evidence, erythrocyte sedimentation rate, C-reactive protein) after joint replacement, post-infection treatment, and postoperative complications were also recorded. The diagnosis and classification of periprosthetic infection was performed according to the 2012 Musculoskeletal Infectious Society criteria [11].

\section{Statistical analysis}

Statistical analysis was performed using SPSS 20.0. For continuous data, the mean \pm standard deviation was computed and data between groups compared using the $t$ test. For the classification data, the composition ratio is expressed, and differences between groups established using the chi-square tests. In all cases, a two-sided test was performed; $p<0.05$ was considered statistically significant.

\section{Results}

\section{Patient general information}

A total of 38,319 cases of hip and/or knee arthroplasty were included in our study. While there was an $8.4 \%$ rise in the number of cases from 2014 to 2015 , no increase was observed between 2015 and 2016 (Table 1). There were $366(0.96 \%)$ revision cases due to PJI over the duration of the study (Table 1).

The mean age of patients who underwent revision surgery due to PJI was $62.3 \pm 13.1$ years (range $21-86$ years)

Table 1 Numbers of hip and knee arthroplasty and periprosthetic infection at the 9 hospitals during 2014-2016

\begin{tabular}{|c|c|c|c|c|c|c|}
\hline \multirow[t]{2}{*}{ Hospital } & \multicolumn{2}{|l|}{2014} & \multicolumn{2}{|l|}{2015} & \multicolumn{2}{|l|}{2016} \\
\hline & Hip & Knee & Hip & Knee & Hip & Knee \\
\hline A & $277(3)$ & $589(10)$ & $269(1)$ & $573(4)$ & $308(2)$ & $688(1)$ \\
\hline B & 1381 (14) & $2242(18)$ & $1508(10)$ & 2031 (14) & 1391 (13) & 2178 (14) \\
\hline C & $274(2)$ & 1115 (8) & $306(2)$ & 1261 (3) & $306(1)$ & $934(6)$ \\
\hline D & $500(9)$ & $1200(14)$ & $500(5)$ & $1650(4)$ & $450(6)$ & 1700 (8) \\
\hline$E$ & $161(2)$ & $284(0)$ & $157(2)$ & $358(3)$ & $146(1)$ & $337(0)$ \\
\hline$F$ & $181(4)$ & 369 (3) & $191(1)$ & $312(1)$ & $189(0)$ & $352(1)$ \\
\hline G & $58(1)$ & 65 (3) & $119(1)$ & $136(1)$ & $126(0)$ & $141(2)$ \\
\hline $\mathrm{H}$ & $330(4)$ & $375(7)$ & $328(1)$ & $353(2)$ & $331(2)$ & $467(1)$ \\
\hline | & $1255(11)$ & 1457 (19) & 1637 (38) & 1439 (33) & $1431(25)$ & 1602 (25) \\
\hline Sum & $4417(50)$ & 7696 (82) & $5015(61)$ & 8114 (75) & $4678(50)$ & 8399 (58) \\
\hline \multirow[t]{2}{*}{ Total } & $12,113(132)$ & & \multirow{2}{*}{\multicolumn{2}{|c|}{13,128 (136) }} & \multirow[t]{2}{*}{ 13,077 (108) } & \\
\hline & 38,319 (366) & & & & & \\
\hline
\end{tabular}

Numbers of periprosthetic infection are indicated in brackets. A, Peking Union Medical College Hospital; B, Chinese PLA General Hospital; C, Beijing Jishuitan Hospital; D, Peking University Third Hospital; E, Peking University People's Hospital; F, Sino-Japanese Friendship Hospital; G, Beijing Chaoyang Hospital; H, Beijing Friendship Hospital; I, Peking University First Hospital 
with a slightly higher proportion of females $(n=205$, $56.0 \%)$. On the other hand, the mean BMI of these patients was $25.6 \pm 3.8 \mathrm{~kg} / \mathrm{m}^{2}$ (range $15.6-38.1 \mathrm{~kg} / \mathrm{m}^{2}$ ). In these patients, $72(19.7 \%)$ were diagnosed with diabetes prior to the primary surgery. The primary surgery majorly involved unilateral joint replacement $(325,88.8 \%)$ with one-stage bilateral joint replacement happening only in 41 patients $(11.2 \%)$. Of note, the majority of the PJI were due to late infections $(318,86.9 \%)$ (Table 2). The overall revision rate after joint replacement was $0.28 \%(109 / 38,319)$ (Table 3).

\section{Hip replacement}

The study recorded 14,110 cases of total hip arthroplasty or femoral head replacement the majority of which were primary hip replacement $(13,317,94.48 \%)$ (Table 1). Among the surgical revision cases, 161 cases were associated with infection mostly after the primary replacement. The proportion of infectious hip revision in the hip replacement cases was $1.14 \%(161 / 14,110)$ while the overall revision rate due to PJI after hip replacement in the 9 hospitals was $0.20 \%(28 / 14,110)$ (Table 3$)$.

Primary hip replacement was occasioned by various conditions the most common being femoral neck fracture $(n=53,32.9 \%)$ and femoral head necrosis $(n=60$, $37.3 \%)$. Other causes were degenerative osteoarthritis, femoral intertrochanteric fracture, developmental dysplasia of the hip, traumatic arthritis, rheumatoid arthritis, ankylosing spondylitis, tuberculosis, congenital hip

Table 2 Demographic and clinical data of patients with periprosthetic infections

\begin{tabular}{llll}
\hline & $\begin{array}{l}\text { Hip arthroplasty } \\
(n=161)\end{array}$ & $\begin{array}{l}\text { Knee arthroplasty } \\
(n=205)\end{array}$ & $p$ \\
\hline Male/female & $98 / 63$ & $63 / 142$ & 0.000 \\
Age (year) & $56.4 \pm 15.0$ & $66.7 \pm 9.3$ & 0.000 \\
BMI (kg/m $\left.{ }^{2}\right)$ & $25.1 \pm 4.1$ & $25.9 \pm 3.6$ & 0.048 \\
Partial/total arthroplasty & $143 / 17$ & $182 / 24$ & 0.758 \\
Primary/revision arthroplasty & $157 / 4$ & $201 / 4$ & 1.000 \\
Diabetes & $29 / 132$ & $43 / 162$ & 0.479 \\
Primary surgery & $47 / 114$ & $102 / 103$ & 0.000 \\
Acute/late infection & $7 / 154$ & $41 / 164$ & 0.000 \\
Infection duration (day) & $608.7 \pm 849.9$ & $400.0 \pm 667.1$ & 0.009 \\
Sinus tract & $39 / 122$ & $52 / 151$ & 0.644 \\
Positive culture & $115 / 46$ & $141 / 64$ & 0.583 \\
Single/multiple species & $76 / 39$ & $111 / 30$ & 0.023 \\
Bacteria resistance & 41 & 28 & 0.004 \\
ESR (mm/1 h) & $41.5 \pm 20.6$ & $49.3 \pm 23.4$ & 0.001 \\
CRP (mg/L) & $24.3 \pm 29.8$ & $33.6 \pm 47.7$ & 0.031 \\
\hline BMI body mass index, ESR erythrocyte sedimentation rate, CRP & \\
C-reactive protein & & &
\end{tabular}

dislocation, hip fracture, and septic arthritis. Unknown causes for hip replacement were reported in 11 cases.

Prior to the primary surgery, $29(18.0 \%)$ patients were diagnosed with diabetes and most of the primary surgeries involved unilateral arthroplasty $(n=143,88.8 \%)$. Late infections (95.7\%) rather than acute infections were the major reasons for surgical revisions. The causes and duration of the infections displayed wide heterogeneity. Over 115 positive cultures were identified from the infected joints with $66 \%(76 / 115)$ arising due to a single species (Table 2). Staphylococcus was the leading bacterial species responsible for infection, followed by Enterococcus, Streptococcus, Klebsiella, Pseudomonas aeruginosa, Escherichia coli, and Propionibacterium. Infections with resistant bacteria $(n=41)$ were also documented with some cultures producing negative results (Table 2).

\section{Knee replacement surgery}

Our study identified 24,209 cases of either total or partial knee arthroplasty (Table 1). Most of these cases $(n=23,443,96.8 \%)$ were for primary knee replacement. Surgical revision cases due to infections after primary replacement accounted for 201 cases with only 4 cases of infections reported after surgical revision. The overall revision rate due to PJI after knee replacement was $0.33 \%(81 / 24,209)$ (Table 3).

The leading causes of knee replacement were degenerative osteoarthritis $(n=163,79.5 \%)$ and femoral neck fracture $(n=53,32.9 \%)$; this was followed by traumatic arthritis, rheumatoid arthritis, gouty arthritis, villonodular synovitis, and femoral intertrochanteric fracture. The reasons for knee replacement in 15 cases remained unknown.

Prior to the primary surgery, $43(21.0 \%)$ patients were diagnosed to be diabetic. Similar to hip replacement, partial replacement $(n=182,88.8 \%)$ rather than total joint replacement was the dominant surgical procedure. The majority of periprosthetic infections were late infections (80\%) with an overall average duration of $400.0 \pm 667.1$ days (range, 2-4934 days). Positive microbial culture was detected in most of the cases (68.8\%), and many of the infections were caused by a single species. Staphylococcus was the leading bacterial species followed by Enterococcus, Escherichia, and Pseudomonas.

\section{Surgical interventions}

The surgical interventions for PJI varied and included, for infected hip replacement, 7 (4.3\%) cases of open debridement with prosthesis retention, 32 (19.9\%) cases of one-stage revisions, 121 (75.2\%) cases of two-stage revision, and $1(0.007 \%)$ case of hip disarticulation. For infected knee replacement surgery, the procedures included $45(22.0 \%)$ cases of open debridement with 
Table 3 Incidence of surgical revision cases in the nine selected hospitals in Beijing, China

\begin{tabular}{|c|c|c|c|c|c|c|c|c|c|c|c|c|}
\hline \multirow{2}{*}{$\begin{array}{l}\text { Year/ } \\
\text { hospital }\end{array}$} & \multicolumn{3}{|c|}{2014} & \multicolumn{3}{|c|}{2015} & \multicolumn{3}{|c|}{2016} & \multicolumn{3}{|c|}{ Total } \\
\hline & Hip & Knee & Total & Hip & Knee & Total & Hip & Knee & Total & Hip & Knee & Total \\
\hline $\bar{A}$ & 1 & 6 & 7 & 0 & 2 & 2 & 0 & 1 & 1 & 1 & 9 & 10 \\
\hline B & 4 & 8 & 12 & 0 & 8 & 8 & 2 & 2 & 4 & 6 & 18 & 24 \\
\hline C & 0 & 2 & 2 & 0 & 2 & 2 & 1 & 2 & 3 & 1 & 6 & 7 \\
\hline D & 4 & 5 & 9 & 1 & 5 & 6 & 1 & 2 & 3 & 6 & 12 & 18 \\
\hline$E$ & 0 & 1 & 1 & 0 & 0 & 0 & 0 & 0 & 0 & 0 & 1 & 1 \\
\hline$F$ & 0 & 2 & 2 & 1 & 0 & 1 & 0 & 0 & 0 & 1 & 2 & 3 \\
\hline G & 0 & 1 & 1 & 0 & 1 & 1 & 0 & 0 & 0 & 0 & 2 & 2 \\
\hline $\mathrm{H}$ & 0 & 1 & 1 & 0 & 0 & 0 & 0 & 0 & 0 & 0 & 1 & 1 \\
\hline | & 8 & 15 & 23 & 2 & 11 & 13 & 3 & 4 & 7 & 13 & 30 & 43 \\
\hline Total & 17 & 41 & 58 & 4 & 29 & 33 & 7 & 11 & 18 & 28 & 81 & 109 \\
\hline
\end{tabular}

A, Peking Union Medical College Hospital; B, Chinese PLA General Hospital; C, Beijing Jishuitan Hospital; D, Peking University Third Hospital; E, Peking University People's Hospital; F, Sino-Japanese Friendship Hospital; G, Beijing Chaoyang Hospital; H, Beijing Friendship Hospital; I, Peking University First Hospital

prosthesis retention, $13(6.3 \%)$ cases of one-stage revision, $143(69.8 \%)$ cases of two-stage revision, and 4 $(0.02 \%)$ cases of knee fusion.

\section{Discussion}

This is the first study in China analyzing the incidence of surgical revision due to PJI using a large sample size. Our findings show a decrease in the overall rates of periprosthetic infection and surgical revision after hip and knee replacement at the nine hospitals in Beijing from 2014 to 2016 (0.48 to $0.14 \%$ ).

Patient-related factors have been implicated to predispose to PJI. Lombardi et al. [12] have proposed that conditions such as obesity and diabetes may increase the risk of periprosthetic infection. On the other hand, Sousa et al. [9] found that the incidence of periprosthetic infection in patients with asymptomatic bacteriuria was significantly higher than that in patients without the condition $(4.3 \%$ vs. $1.4 \%)$. In another case, a prospective study conducted by Peng et al. [13] showed that the application of povidone-iodine for nasal disinfection before orthopedic surgery can effectively reduce the colonization of methicillin-resistant Staphylococcus aureus.

The surgical team and surgical procedure have also been identified as risk factors for periprosthetic infection. In their work, Leijtens et al. [14] showed that intraoperative hypothermia is associated with increased risk of infection after total knee arthroplasty. In a different study, Panahi et al. [15] found that the frequency of opening of the operating room door per minute influenced the infection rates. Bacterial contamination of the surgical room was thus linked to an increase in the infection rate. Therefore, the implementation of measures to prevent and control contamination may help to reduce the incidence of periprosthetic infection $[16,17]$.
There is a consensus that the two-stage revision with antibiotic bone cement spacer is the gold standard for the treatment of chronic periprosthetic infection $[18,19]$. This was also the treatment method adopted for most of the patients with periprosthetic infections in our study. However, this surgical procedure has a long course of treatment and is demanding with regard to surgical skills. Furthermore, the procedure is also associated with the risk of serious loss of bone mass during operation and postoperative complications.

The feasibility and efficacy of the one-stage surgical revision for the treatment of periprosthetic infection have been explored [20-23]. It has been shown that the onestage revision produces comparable treatment outcomes to those of the two-stage revision [24, 25]. In 2015, an international expert consensus recommended the use of the two-stage surgical revision instead of the one-stage revision for patients with severe soft tissue injury, positive culture of resistant bacteria, or sinus tract formation [26].

In the present study, $22.0 \%$ of the patients with knee prosthetic infections were treated with open debridement and prosthesis retention. Compared to revision surgery, this procedure has better postoperative knee function and quality of life as more bone mass is retained and there is less risk of postoperative complications [27]. In addition, the procedure is less demanding on the level of surgical skill and takes a shorter operation time. In one study, the reported success rate of knee debridement in treating periprosthetic infection was $44-75 \%[27,28]$. It has been suggested that sinus tract is a risk factor for the failure of knee debridement and a contraindication for retaining prostheses in managing periprosthetic infection [29]. Marculescu et al. found that patients with sinus tract had a survival rate of only $29 \%$ after 2 years of primary surgery, 
contrasting with the survival rate of $64 \%$ in those without sinus tract [30].

In a study by Bradbury et al. and Barberán et al., the success rate of open debridement with prosthesis retention in treating periprosthetic infection patients with a positive culture of resistant bacteria was relatively low (18-28.6\%) [29, 31]. Insert exchange in debridement has been shown to be effective in eradicating infection [32-34]. Currently, there is controversy over the appropriate timing of open debridement. The failure rate of open debridement in treating periprosthetic infection significantly increases beyond a certain time after total knee arthroplasty, which varies from 15 days to 1 month in different studies [30,31,35].

Although providing useful insights, our study is not devoid of limitations. First, the retrospective nature of the study might introduce bias since our survey was limited to the available documented data. Second, patients who were treated using non-surgical methods for mild infections were not included in our study thereby affecting the composition of the study pool. Third, bacterial culture was only performed for the first and not subsequent episodes of infections. The spectrum of microorganisms responsible for infections may, therefore, not be fully representative of the causative agents of infections. Finally, the sampled patient population was mainly from the northern region of China. It may therefore be impossible to extrapolate these findings to the whole of China.

\section{Conclusions}

The overall rate of periprosthetic infection and surgical revision after hip or knee joint arthroplasty in Beijing, China, was $0.96 \%$. The two-stage revision was the most common surgical method for the treatment of periprosthetic infection, and most infections were caused by Staphylococcus. We recommend that surgical methods for the treatment of periprosthetic infection be selected considering a patient's clinical status and the costeffectiveness of the procedure.

\section{Abbreviations}

BMl: Body mass index; PJl: Periprosthetic joint infection

\section{Acknowledgements}

None

\section{Authors' contributions}

$P H, W L$, and $W X$ designed the experiments. CJ, ZY, TH, and $L J$ carried out the experiments. GW, LY, QT, GA, and CY analyzed the experimental results. PH and WL wrote the manuscript. WX approved the manuscript. All authors read and approved the final manuscript.

\section{Funding}

None

\section{Availability of data and materials}

All data generated or analyzed during this study are included in this published article.

\section{Ethics approval and consent to participate}

N/A

\section{Consent for publication}

N/A

\section{Competing interests}

The authors declare that they have no competing interests.

\section{Author details}

${ }^{1}$ Department of Orthopedics, Peking Union Medical College Hospital, CAMS \& PUMC, No.1 Shuaifuyuan, Wangfujing, Dongcheng District, Beijing 100730, China. ${ }^{2}$ Department of Orthopedics, Chinese PLA General Hospital, Beijing 100853, China. ${ }^{3}$ Department of Orthopedics, Beijing Jishuitan Hospital, Beijing 100035, China. ${ }^{4}$ Department of Orthopedics, Peking University Third Hospital, Beijing 100083, China. ${ }^{5}$ Department of Orthopedics, Peking University People's Hospital, Beijing 100044, China. ${ }^{6}$ Department of Orthopedics, Sino-Japanese Friendship Hospital, Beijing 100029, China. ${ }^{7}$ Department of Orthopedics, Beijing Chaoyang Hospital, Capital Medical University, Beijing 100020, China. ${ }^{8}$ Department of Orthopedics, China Rehabilitation Research Center Beijing Boai Hospital, Beijing 100068, China. ${ }^{9}$ Department of Orthopedics, Beijing Friendship Hospital, Capital Medical University, Beijing 100050, China. ${ }^{10}$ Department of Orthopedics, Peking University First Hospital, Beijing 100034, China.

Received: 26 August 2019 Accepted: 17 December 2019

Published online: 26 December 2019

\section{References}

1. Kurtz S, Ong K, Lau E, Mowat F, Halpern M. Projections of primary and revision hip and knee arthroplasty in the United States from 2005 to 2030. J Bone Joint Surg Am. 2007;9:80-5

2. Zmistowski B, Karam JA, Durinka JB, Casper DS, Parvizi J. Periprosthetic joint infection increases the risk of one-year mortality. J Bone Joint Surg Am. 2013;5:2177-84.

3. Sampedro MF, Patel R. Infections associated with long-term prosthetic devices. Infect Dis Clin N Am. 2007:1:85-819x

4. Clohisy JC, Calvert G, Tull F, McDonald D, Maloney WJ. Reasons for revision hip surgery: a retrospective review. Clin Orthop Relat Res. 2004;(429):188-92.

5. Crowe JF, Sculco TP, Kahn B. Revision total hip arthroplasty: hospital cost and reimbursement analysis. Clin Orthop Relat Res. 2003;(413):175-82.

6. Paprosky WG, Weeden SH, Bowling JW Jr. Component removal in revision total hip arthroplasty. Clin Orthop Relat Res. 2001;(393):181-93.

7. Kurtz SM, Lau E, Schmier J, Ong KL, Zhao K, Parvizi J. Infection burden for hip and knee arthroplasty in the United States. J Arthroplast. 2008; 23:984-91.

8. Lübbeke A, Zingg M, Vu D, Miozzari HH, Christofilopoulos P, Uçkay I, Harbarth S, Hoffmeyer P. Body mass and weight thresholds for increased prosthetic joint infection rates after primary total joint arthroplasty. Acta Orthop. 2016;7:132-8.

9. Sousa R, Muñoz-Mahamud E, Quayle J, Dias da Costa L, Casals C, Scott P, Leite P, Vilanova P, Garcia S, Ramos MH, Dias J, Soriano A, Guyot A. Is asymptomatic bacteriuria a risk factor for prosthetic joint infection? Clin Infect Dis. 2014;59:41-7.

10. Kane P, Chen C, Post Z, Radcliff K, Orozco F, Ong A. Seasonality of infection rates after total joint arthroplasty. Orthopedics. 2014;37:e182-6.

11. Parvizi J, Zmistowski B, Berbari EF, Bauer TW, Springer BD, Della Valle CJ, et al. New definition for periprosthetic joint infection: from the Workgroup of the Musculoskeletal Infection Society. Clin Orthop Relat Res. 2011;469:2992-4

12. Lombardi A, Berend K, Adams J. Why knee replacements fail in 2013: patient, surgeon, or implant? Bone Joint J. 2014;96-B:101-4

13. Peng H, Wang L, Zhai J, Weng XS, Feng B, Wang W. Effectiveness of preoperative decolonization with nasal povidone iodine in Chinese patients undergoing elective orthopedic surgery: a prospective cross-sectional study. Braz J Med Biol Res. 2017;51:e6736.

14. Leijtens B, Koëter M, Kremers $K$, Koëter S. High incidence of postoperative hypothermia in total knee and total hip arthroplasty: a prospective observational study. J Arthroplast. 2013;28:895-8. 
15. Panahi $\mathrm{P}$, Stroh M, Casper D, Parvizi J, Austin MS. Operating room traffic is a major concern during total joint arthroplasty. Clin Orthop Relat Res. 2012;470:2690-4.

16. Knobben BA, van Horn JR, van der Mei HC, Busscher HJ. Evaluation of measures to decrease intra-operative bacterial contamination in orthopaedic implant surgery. J Hosp Infect. 2006;62:174-80.

17. Ibrahim MS, Khan MA, Nizam I, Haddad FS. Peri-operative interventions producing better functional outcomes and enhanced recovery following total hip and knee arthroplasty: an evidence-based review. BMC Med. 2013;11:37.

18. Cooper HJ, Della Valle CJ. The two-stage standard in revision total hip replacement. Bone Joint J. 2013;95-B:84-7.

19. Lichstein P, Su S, Hedlund H, Suh G, Maloney WJ, Goodman SB, Huddleston $\mathrm{Jl}$ 3rd. Treatment of periprosthetic knee infection with a two-stage protocol using static spacers. Clin Orthop Relat Res. 2016:474:120-5.

20. Callaghan JJ, Katz RP, Johnston RC. One-stage revision surgery of the infected hip. A minimum 10-year followup study. Clin Orthop Relat Res. 1999;(369):139-43.

21. Winkler H, Stoiber A, Kaudela K, Winter F, Menschik F. One stage uncemented revision of infected total hip replacement using cancellous allograft bone impregnated with antibiotics. J Bone Joint Surg Br. 2008; 90:1580-4.

22. Rudelli S, Uip D, Honda E, Lima AL. One-stage revision of infected total hip arthroplasty with bone graft. J Arthroplast. 2008:23:1165-77.

23. Parkinson RW, Kay PR, Rawal A. A case for one-stage revision in infected total knee arthroplasty? Knee. 2011;18:1-4

24. George D, Haddad F. One-stage exchange arthroplasty: a surgical technique update. J Arthroplast. 2017:32:S59-62.

25. Kunutsor S, Whitehouse M, Lenguerrand E, Blom AW, Beswick AD; INFORM Team. Re-infection outcomes following one- and two-stage surgical revision of infected knee prosthesis: a systematic review and meta-analysis. PLoS One. 2016;11: e0151537.

26. Jiranek W, Waligora A, Hess S, Golladay GL. Surgical treatment of prosthetic joint infections of the hip and knee: changing paradigms? J Arthroplast. 2015:30:912-8

27. Gardner J, Gioe T, Tatman P. Can this prosthesis be saved?: implant salvage attempts in infected primary TKA. Clin Orthop Relat Res. 2011:469:970-6.

28. Cury Rde P, Cinagawa EH, Camargo OP, Honda EK, Klautau GB, Salles MJ. Treatment of infection after total knee arthroplasty. Acta Ortop Bras. 2015; 23:239-43.

29. Bradbury T, Fehring T, Taunton M, Hanssen A, Azzam K, Parvizi J, Odum SM. The fate of acute methicillin-resistant Staphylococcus aureus periprosthetic knee infections treated by open debridement and retention of components. J Arthroplast. 2009:24:101-4.

30. Marculescu CE, Berbari EF, Hanssen AD, Steckelberg JM, Harmsen SW, Mandrekar JN, Osmon DR. Outcome of prosthetic joint infections treated with debridement and retention of components. Clin Infect Dis. 2006:42:471-8.

31. Barberán J, Aguilar L, Carroquino G, Giménez MJ, Sánchez B, Martínez D, Prieto J. Conservative treatment of staphylococcal prosthetic joint infections in elderly patients. Am J Med. 2006;19:93.e997-10.

32. Zhang C, Yan C, Chan P, Ng FY, Chiu KY. Polyethylene insert exchange is crucial in debridement for acute periprosthetic infections following total knee arthroplasty. J knee surg. 2017;30:36-41.

33. Kim J, Bae J, Lee S, Cho WT, Lim HC. The parameters affecting the success of irrigation and debridement with component retention in the treatment of acutely infected total knee arthroplasty. Clin Orthop Surg. 2015;7:69-76.

34. Choi H, von Knoch F, Zurakowski D, Nelson SB, Malchau H. Can implant retention be recommended for treatment of infected TKA? Clin Orthop Relat Res. 2011;469:961-9.

35. Kuiper J, Vos S, Saouti R, Vergroesen DA, Graat HC, Debets-Ossenkopp YJ, et al. Prosthetic joint-associated infections treated with DAIR (debridement, antibiotics, irrigation, and retention): analysis of risk factors and local antibiotic carriers in 91 patients. Acta Orthop. 2013;84:380-6.

\section{Publisher's Note}

Springer Nature remains neutral with regard to jurisdictional claims in published maps and institutional affiliations.

Ready to submit your research? Choose BMC and benefit from:

- fast, convenient online submission

- thorough peer review by experienced researchers in your field

- rapid publication on acceptance

- support for research data, including large and complex data types

- gold Open Access which fosters wider collaboration and increased citations

- maximum visibility for your research: over $100 \mathrm{M}$ website views per year

At BMC, research is always in progress.

Learn more biomedcentral.com/submissions 